\title{
Estética y Política: el Debate Contemporáneo en TORNO A LAS Formas de LA REPRESENTACIÓN
}

\author{
María Verónica Galfione ${ }^{l}$
}

\begin{abstract}
RESUMEN: Tanto desde el punto de vista teórico como desde una perspectiva práctica, el fenómeno de la "estetización" no parece ser portador de buenos augurios. En el ámbito teórico, la estetización ha sido vinculada con la crisis de los discursos orientados en términos de verdad, mientras que en el terreno práctico, ella ha sido asociada a ciertos procesos culturales que conducirían a la debacle de los principios normativos. Dejando de lado la problemática teórica, el presente trabajo se concentra en el debate en torno al fenómeno práctico de la estetización de la política. En primer lugar, nos remontamos a la historia de la condena filosófica de la estetización de la esfera política para ocuparnos luego, en un segundo momento, de algunas posiciones esteticistas y antiesteticistas de finales del siglo XX. Posteriormente, procuramos avanzar en una redescripción de esta problemática que nos permita rescatar un sentido productivo de lo estético para el pensamiento político. Para esto último, nuestro trabajo se apoya en las reflexiones de la actual coeditora de la Neue Zeitschrift für Sozialforschung, Juliane Rebentisch. Tomando como parámetro algunos de los supuestos de sus investigaciones, aquí intentaremos demostrar hasta qué punto la estetización de la vida política puede contribuir al desarrollo de una concepción renovada de esta última.
\end{abstract}

PALABRAS CLAVES: Estetización de la política. Experiencia estética. Reflexión.

\section{INTRODUCCIÓN}

Tanto desde el punto de vista teórico como desde una perspectiva práctica, bajo el lema de la "estetización" no parece ser posible interpretar nada particularmente bueno. En el ámbito teórico, las tendencias estetizantes han sido vinculadas con la crisis de los discursos orientados en términos de verdad, mientras que en el terreno práctico, las mismas han sido asociadas a ciertos fenómenos culturales que conducirían a la debacle de la esfera pública y de sus principios normativos (BROMBACH, 2010, p.7). Dejando de lado la problemática teórica, nos proponemos reconstruir en el presente trabajo las líneas principales del debate en torno al fenómeno de la estetización de la cultura política que ha tenido lugar en Alemania desde finales del siglo XX. Para ello nos

1 Facultad de Lenguas / Facultad de Ciencias Sociales. Universidad Nacional de Córdoba (UNC). Argentina. Consejo Nacional de Investigaciones Científicas y Técnicas (CONICET). Argentina veronicagalfione@yahoo.com.ar 
remontaremos, en una primera instancia, a la historia de la condena filosófica de la estetización de la esfera pública. Sobre el trasfondo de una concisa reconstrucción de la historia del problema, nos ocuparemos luego del diagnóstico de Wolfgang Welsch (1996), representante de la postura postmoderna en el debate actual en torno al problema de la estetización, y de Rüdiger Bubner (1989), defensor de una posición contraria a las nuevas tendencias culturales. Posteriormente, procuraremos avanzar en una redescripción de esta problemática que nos permita rescatar un sentido productivo de lo estético para el pensamiento político. Para esto último nos basaremos en las reflexiones que han sido desarrolladas en los últimos años por Juliane Rebentisch, quien descubre en la estetización de la política, en tanto erosión de su normatividad, un recurso adecuado para el desarrollo de una importante renovación de la misma (REBENTISCH, 2012a; 2010, p.113-118). ${ }^{2}$

\section{Perspectivas Clásicas frente al problema de la estetización}

Ya desde sus orígenes, la reflexión filosófica se caracterizó por condenar a la apariencia estética en función de su capacidad para proyectar determinadas actitudes corrosivas sobre las diversas esferas normativas de la vida social. En este sentido pueden ser leídos aquellos famosos pasajes en los cuales el Platón de la República desterraba a los poetas de la ciudad. Puesto que no era en virtud del mero contenido engañoso de sus obras que los poetas debían permanecer fuera de los límites de la polis sino del medio que empleaban para la representación de las diversas historias mitológicas. Esto es, desde la perspectiva de Platón el problema radicaba en la propia apariencia estética en la medida en que esta contribuía a desdibujar aquellos límites que permitían diferenciar lo falso de lo verdadero. En este punto, el carácter subversivo de la apariencia estética se desprendería de la capacidad de la misma para cuestionar aquellos presupuestos ontológicos que hacían posible el enjuiciamiento objetivo acerca de la propia esfera de la realidad:

Así mi querido Glaucón - sostenía Platón en el libro X de la Repúblicacuando oigas decir a los admiradores de Homero que este poeta ha formado la Grecia, y que, leyéndole, se aprende a gobernar y conducir bien los negocios humanos, y que lo mejor que se puede hacer es someterse a sus preceptos, deberás tener toda clase de miramientos y de consideraciones con los que empleen este lenguaje, como si estuvieran dotados del mayor éxito, y hasta concederles que Homero es el más grande poeta y el primero

${ }^{2}$ Una posición similar puede encontrarse en Christoph MENKE (2010a, p.11-22). 
entre los trágicos; pero al mismo tiempo no pierdas de vista que en nuestro Estado no podemos admitir otras obras de poesía que los himnos a los dioses y los elogios de los hombres grandes; porque tan pronto como des cabida a la musa voluptuosas, sea épica, sea lírica, el placer y el dolor reinarán en el Estado en lugar de las leyes, en lugar de esta razón, cuya excelencia han reconocido todos los hombres en todos los tiempos. (PLATÓN, 1973, X, p.607).

También en la obra de Jean-Jacques Rousseau es posible encontrar una crítica similar a la apariencia estética y al influjo corrosivo de la misma sobre los demás planos de la vida social. La diferencia entre ambos planteos resulta dependiente del posicionamiento político que asumieron los dos autores mencionados. Puesto que, si Platón asociaba la disolución estética de los límites entre esencia y apariencia con el proceso de democratización, para Rousseau la estetización de las relaciones políticas ponía en peligro la posible instauración de una república de carácter democrático (REBENTISCH, 2011a, p.1). Esto es, Platón caracterizaba al régimen democrático como aquel sistema en el cual las tendencias estetizadoras alcanzaban su punto culminante o, dicho en otros términos, como aquella forma política que permitía y favorecía la disolución de las diversas distinciones que hacían posible el ordenamiento racional de los asuntos comunes. Para Rousseau, en cambio, la preponderancia de la dimensión estética no atentaba contra determinaciones ontológicas externas sino que conducía, más bien, al extrañamiento de los individuos con respecto a su esencia colectiva y entorpecía, de esta forma, la constitución de una voluntad auténticamente democrática.

Según lo entendía Rousseau, la influencia perniciosa de la dimensión estética llegaba a su máxima expresión en el caso del teatro. Puesto que, el trato asiduo con las artes representativas educaba a los ciudadanos en el peligroso juego de la transfiguración. Como señalaba el autor en su famosa discusión con D'Alembert en torno a la posibilidad de instaurar un teatro en Ginebra, el inocente intercambio de roles que tenía lugar en la esfera teatral atentaba contra la transparencia que resultaba necesaria en orden a ejecutar una acción de carácter colectivo. Dicho en otros términos, las artes escénicas hacían el uso generalizado del principio de la disimulación y contribuían, de esta forma, al entrenamiento de los individuos en el arte de establecer distinciones entre aquello que eran y el modo en que se presentan ante los demás. Pues, “¿Cuál es el talento del comediante?", se preguntaba Rousseau, sino 
[...] el arte de fingir, de aparentar otro carácter que el propio, de aparecer diferente a lo que se es, de apasionarse a sangre fría, de decir algo distinto a lo que se piensa, tan naturalmente como si en efecto se lo pensara; y, en fin, el de olvidar el propio lugar para tomar uno ajeno. (ROUSSEAU, 1996, p.165-166).

En efecto, el comediante se caracterizaba por su capacidad para asumir diferentes roles y por su disposición a hacerlo en función de los intereses que le imponía su profesión. Recalcando las connotaciones políticas de su descripción, Rousseau hacía referencia al hecho de que el comediante "[...] se ofrec[ía] en representación por dinero, se somet[ía] a la ignominia y a las afrentas cuyo derecho de infligir se compra [ba]; y en el que pon[ía] públicamente su persona en venta” (ROUSSEAU, 1996, p.165-166).

Como puede observarse en el último fragmento citado, la crítica rousseaniana a la estetización de la política no solo se orientaba a condenar la confusión entre el ser y la apariencia, que introducía el principio de la representación, sino que denunciaba, además, la propensión a subordinar los intereses comunes al beneficio particular. Con esto último, Rousseau enfatizaba el vínculo existente entre las actitudes esteticistas y el menosprecio del espacio común. Sin embargo, el mismo aún no se mostraba dispuesto a caracterizar dichas conductas corrosivas en términos de una huída individual con respecto a las determinaciones objetivas en general. Dicho de otros términos, Rousseau no remitía el fenómeno de la estetización al proceso moderno de subjetivación de los principios normativos, sino que lo entendía como el resultado del progresivo desplazamiento de los juicios racionales por medio de actitudes que se hallaban asociadas a la mera sensibilidad (MENKE, 2010a, p.20).

\section{ESTETICISMO Y SUBJETIVIDAD}

Este último giro, que se hallaba llamado a ocupar un lugar central en la condena contemporánea del ámbito estético, puede registrarse en la crítica hegeliana del romanticismo de Jena. Desde la perspectiva de Hegel, la tendencia de los jóvenes románticas a pensar la obra de arte en términos de ironía suponía el establecimiento de una relación de identidad entre la representación artística y la expresión de contenidos de carácter estrictamente subjetivo (MENKE, 2010b, p.776) No obstante, Hegel no se limitaba a denunciar así la falta de objeto del arte romántico, sino que extraía de este 
hecho conclusiones relativas a las implicancias teórico-prácticas del interés mismo por los fenómenos estéticos. De la ocupación exclusiva de la estética y de la representación artística con los estados de ánimo de la subjetividad se inferiría, para Hegel, tanto el menosprecio del esteta por las determinaciones objetivas como la complicidad del mismo con las propias relaciones de dominio. Con respecto al primer punto, resulta ilustrativa la identificación de la subjetividad irónica con el mal, que realizaba Hegel en la Filosofía del Derecho, ${ }^{3}$ con respecto al segundo, en cambio, es de particular interés la inversión de la conciencia romántica que proponía Hegel en las Lecciones sobre estética. Pues, tomando como punto de partida la representación artística, Hegel intentaba poner en evidencia hasta qué punto la independencia de la subjetividad irónica con respecto a todo contenido de carácter objetivo traía aparejado un distanciamiento del ámbito práctico y una pérdida absoluta de la libertad (HEGEL, 1999, p.211). ${ }^{4}$ Ambas ideas aparecían condensadas en aquel pasaje de las Lecciones sobre filosofía del derecho en el cual Hegel sostenía: "[...] la ironía es esta conciencia de poder simplemente jugar con todo y de reinar incluso sobre lo noble y lo excelente y de permitírselo hacer. Lo positivo en esta ironía es la vanidad, la vanidad en todo lo que emprendo. Yo soy lo vano. La ironía es justamente la forma, la cima, que puede ser de una manera o de otra, la forma de la vacuidad" (HEGEL, 1970, p.279).

Bajo diferentes formas y con distintos matices, la condena de Hegel al esteticismo romántico fue reproducida y profundizada a lo largo del todo el siglo XIX. Constituyen documentos importantes de este proceso tanto La escuela romántica de Heinrich Heine, de 1833 (HEINE, 2007), como el artículo de Arnold Ruge y Theodor Echtermeyer, "El protestantismo y romanticismo", aparecido en el Anuario de ciencia y arte alemán de Halle (Hallische Jahrbürcher für deutsche Wissenschaft und Kunst) entre octubre de 1839 y marzo de 1840 (RUGE; ECHTERMEYER, 1999, p.192 - 225). ${ }^{5}$ Sin

\footnotetext{
3 "Das Selbstbewußtsein in der Eitelkeit aller sonst geltenden Bestimmungen und in der reinen Innerlichkeit des Willens ist ebensosehr die Möglichkeit, das an und für sich Allgemeine, als die Willkür, die eigene Besonderheit über das Allgemeine zum Prinzipe zu machen und sie durch Handeln zu realisieren - böse zu sein.... Die höchste Form endlich, in welcher diese Subjektivität sich vollkommen erfaßt und ausspricht, ist die Gestalt, die man mit einem von Platon erborgten Namen Ironie genannt hat [...]" (HEGEL, 1970, p.261)

${ }^{4}$ En el juicio negativo de Hegel pesaba la filiación política de algunos de sus máximos representantes, pero también se mezclaba el talante "impertinente" de los primeros románticos de Jena. Con respecto a este punto, se puede consultar FRITHJOF (1983, p.177s).

${ }^{5} \mathrm{El}$ romanticismo es asociado aquí a la reforma protestante en la medida en que el mismo se había caracterizado por reafirmar el principio de la subjetividad. Desde la perspectiva de los autores, sin
} 
embargo, la crítica al escapismo esteticista experimentaría su punto culminante recién hacia comienzos del siglo XX.

En el nuevo contexto epocal, tanto la asociación hegeliana entre esteticismo y subjetivismo como su identificación de tales términos con el mal y el extrańamiento con respecto a toda praxis social, fueron retomadas por pensadores procedentes de las más diversas tradiciones políticas y filosóficas. Así Martin Heidegger, por ejemplo, se encargaría de poner en cuestión en sus lecciones sobre Nietzsche de 1936-1945 aquellas perspectivas que procuraban interpretar el surgimiento del sujeto estético en términos de una alternativa o de una crítica al concepto moderno de subjetividad (CASSIRER, 1981, p.384-387; Cf. MENKE, 2011a, p.274). Desde la perspectiva de Heidegger, la concentración de la estética moderna en el análisis de los estados sentimentales del hombre representaba el resultado y la consumación de la propia metafísica moderna de la subjetividad. Lejos de hacer posible nuevas formas de libertad, la misma constituía la expresión más lograda de un proyecto que había convertido al ente en un estímulo para la experiencia subjetiva (HEIDEGGER, 1961/II, p.195; 1961/I, p.99) y que había hecho posible, de esta forma, el imperio de un principio de carácter impersonal (Das man) (HEIDEGGER, 1986, p.126s).

\section{LA ESTETIZACIÓN DEL MUNDO DE LA VIDA}

El tipo de crítica al subjetivismo estético por mencionamos en el pasaje anterior y que, pese a las diferencias políticas, es posible reencontrar tanto en Carl Schmitt (2001, p.161-162) como en las diferentes etapas de la obra de Georg Lukács ${ }^{6}$, sufrirá una importante rectificación hacia finales del siglo XX. De lo nuevo rumbo que asume la discusión contemporánea acerca del fenómeno de la estetización da cuenta el análisis del mismo que propone Wolfgang Welsch durante la última década del siglo XX. Este autor se hace eco de aquellas perspectivas que, en continuidad con los grandes diagnósticos de comienzos del siglo XX, constataban el avance indiscriminado del proceso

embargo, el romanticismo había adoptado ese principio de una manera unilateral, puramente anímica, y dado lugar así a una subjetividad vacía e insustancial (RUGE; ECHTERMEYER, 1999, p.196).

${ }^{6}$ La crítica de lukacsiana al subjetivismo estético ya se encuentra presente en algunos de sus escritos de juventud tales como Cultura estética o El alma y las formas, por más que en este último texto Lukács introduzca conceptos de procedencia romántica tales como el de ironía o el de novela. (Cf. LUKÁCS, 1997, p.13-26; 1971, p.1987) Con algunas modificaciones, esta crítica volverá a aparecer en escritos más tardíos como Fortschritt und Reaktion in der deutschen Literatur (1950). 
de estetización. En este sentido, resulta necesario recordar la interpretación de la progresiva estilización, escenificación o embellecimiento de las relaciones sociales que proponía Rüdiger Bubner hacia 1987 por medio del concepto de "estetización del mundo de la vida". Con este concepto, Bubner hacía referencia al increíble despliegue que había experimentado la esfera estética durante el último tercio del siglo XX y en función del cual esta había llegado a convertirse en un principio directriz. Según el autor, "[...] la estetización del mundo de la vida" abarcaba "[...] desde los carteles propagandísticos omnipresentes [...] pasando por la escenificación masiva que tiene lugar semanalmente de la subculturas del deporte y de la música, hasta la mezcla evidente de la política y la religión con instancias festivas" (1989, p.149).

Desde el punto de vista de Bubner, la acelerada multiplicación de los fenómenos estéticos que tenía lugar en todos los terrenos de la vida cotidiana, social y política, resultaba dependiente tanto de la nivelación de la esfera estética que se producía por medio de la mezcla entre estilos populares y elitistas, como de la disolución de la categoría clásica de obra de arte (BUBNER, 1989, p.33). Este último proceso, que encontraba sus orígenes en las vanguardias artísticas, había alcanzado su consumación en el diseño y había dado lugar así, según afirmaba Bubner, a una cultura que privilegiaba el atractivo superficial:

En la época de los medios de comunicación -concluía el autor- triunfa la tendencia a transformar cualquier contenido en una imagen para el gran público y a reclutar al público, por otra parte, como actor. La acción social se convierte en un comportamiento de exhibición, los sujetos estilizan sus deseos y sus intereses de tal manera que estos se presentan como poses. La realidad renuncia a su dignidad ontológica en pos de una apariencia que es aplaudida por todos. (BUBNER, 1989, p.150).

En consonancia con Bubner, Welsch advierte el progresivo embellecimiento de las fachadas y de los cuerpos (WELSCH, 1996, p.20), y se hace eco de la definitiva reducción de los principios normativos a patrones de carácter eminentemente estético. ${ }^{7}$ Sin embargo, el autor mencionado toma distancia con respecto al diagnóstico de Bubner en un punto significativo. Pues, Welsch ya no se encuentra dispuesto a interpretar las tendencias estetizadoras contemporáneas en términos de una radicalización de la concepción moderna de la subjetividad. Desde el punto de Welch, solo sería posible interpretar la disolución de las determinaciones normativas como el resultado del

${ }^{7}$ Según sostiene Welsch, "[...] la ética [...] se ha convertido en una subdisciplina de la estética” (1996, p.44). 
encumbramiento de una subjetividad de carácter arbitrario a costa de realizar una lectura demasiado estrecha de las grandes transformaciones filosóficas y sociales que han tenido lugar desde finales del siglo XVIII.

Contra la interpretación conservadora de Bubner, Welsch procura demostrar la dependencia de fenómenos tales como la expansión de la industria cosmética, el embellecimiento de los espacios urbanos o el desplazamiento del contenido por medio de su presentación, con respecto a determinados procesos de transformación que han tenido su origen en el ámbito productivo. Desde su perspectiva, la posibilidad de intervenir de manera inteligente en la microestructura de la realidad material habría puesto en evidencia hasta qué punto la posibilidad de una manipulación de esta última no se desprendía del incremento de la fuerza subjetiva sino que se hallaba enraizada, más bien, en su propia falta de determinación. En este sentido, la sorpresa de los expertos actuales ante los nuevos logros en materia de producción ya no tendría por objeto la falta de límite del poder humano de intervención. A diferencia de lo que había sucedido en épocas anteriores, dicha sorpresa se desprendería, para Welsch, de la comprobación empírica de la falta de resistencia que es capaz de ejercer la propia realidad (WELSCH, 1996, p.15). "La estetización actual” - señalaba Welsch - "no tiene que ver con los bellos espíritus, la musa posmoderna de la diversidad o con estrategias económicas superficiales sino que resulta de cambios tecnológicos fundamentales, de hechos contundentes en el ámbito de la producción" (1996, p.15).

Pero el análisis de Welsch no se limita a remitir la disolución del concepto de realidad a la esfera de la producción sino que avanza hasta interpretar el fenómeno mencionado en términos estrictamente filosóficos. Recién en este contexto resulta plenamente visible la distancia que media entre la concepción de Welsch y los viejos programas estéticos de finales del siglo XVIII. Pues, si estos aspiraban a identificar verdad y belleza, ${ }^{8}$ para Welsch, las tendencias estetizadoras actuales traerían aparejada la disolución misma del concepto de verdad. En este punto, el autor se apoya en aquellas perspectivas filosóficas que, desde Nietzsche en adelante, se han encargado de poner en evidencia el procedimiento artístico-productivo que ha hecho posible el surgimiento de una representación sólida de la realidad. El objetivo de Welsch es demostrar la relación de dependencia que existe entre el embellecimiento de las superficies y la estetización progresiva de nuestras perspectivas ontológicas. Pues, esta

8 "La verdad y el bien - es posible leer en el "Más antiguo programa del idealismo alemán" - se hermanan en la belleza” (HEGEL, 1979, p.235). 
crítica a la prioridad ontológica del concepto de realidad, le permite a Welsch rechazar aquellas concepciones filosóficas que interpretan las tendencias estetizadoras actuales en términos de una simple usurpación. Desde el punto de vista de Welsch, el proceso de estetización no conduciría a la disolución de la verdad ni traería aparejada la destrucción de la ciencia, la ilustración y la razón. Ya que, lejos de entorpecer el acceso al núcleo de la verdadera realidad, el mismo revelaría, más bien, el carácter ficticio de la propia distinción entre apariencia y realidad. En este sentido afirma Welsch: „la realidad, que una vez fue considerada firme, se muestra como transformable, susceptible de nuestras combinaciones y abierta para la realización de cualquier deseo estéticamente bosquejado" (1996, p.14-15). Welsch caracteriza en términos de "estetización epistemológica" a este proceso por medio del cual aquellas características que, hasta el momento, habían sido predicadas de las producciones artísticas son proyectadas hacia el ámbito de lo real: „Ya no buscamos ningún fundamento primero o último sino que la realidad asume para nosotros un aspecto que hasta entonces sólo conocíamos del arte -la constitución de lo producido, de lo modificable, de lo no vinculante, de la oscilación" (WELSCH, 1996, p.21).

\section{El IMPERATIVO ESTÉTICo}

Como puede observarse, el diagnóstico de Welsch acerca de las tendencias estetizadoras contemporáneas asume un carácter afirmativo. Pues, el autor descubre tras ellas la presencia de un impulso que tiende a la libre configuración de ámbitos cada vez más extensos de la vida social. Sin embargo, nuestro interés en la lectura que realiza Welsch no se desprende de su posición afirmativa frente a la generalización de los principios estéticos, sino del hecho de que la misma logra poner en evidencia el carácter ontológico de las trasformaciones actuales. Como señalábamos más atrás, Welsch desplaza el problema de la estetización desde el ámbito subjetivo hasta la esfera de lo real. Puesto que, alejándose de aquellas lecturas que lo interpretaban como el corolario de la progresiva independización de la subjetividad con respecto a las determinaciones externas, Welsch procura adjudicarle rasgos manifiestamente antisubjetivos. Desde su punto de vista, la estetización actual supondría una crítica radical del concepto moderno de subjetividad en la medida en que pondría de manifiesto la absoluta dependencia del yo con respecto a procesos constructivos que tendrían lugar en el ámbito de la producción. En este marco resulta comprensible el hecho de que, aun cuando Welch le atribuya un carácter artístico -esto es, producido, no vinculante y modificable- a la realidad social o 
material, no le conceda al sujeto ningún papel en la determinación del rumbo o del sentido de tales procesos constructivos. Por cierto, el propio sujeto llega a presentarse ahora como un producto más de las propias relaciones productivas.

El giro que introduce la interpretación de Welsch en este punto resulta importante por dos motivos. En primer lugar, la misma pone en cuestión aquellas lecturas que descubrían en el menosprecio del esteta por las determinaciones objetivas un momento de libertad con respecto al ámbito social. Pues, en el contexto actual, ese mismo desprecio ha pasado a convertirse en un momento constitutivo de los propios procedimientos que tienen lugar en el ámbito de la producción. Pero este diagnóstico no solo problematiza las lecturas subjetivistas del fenómeno de la estetización sino que relativiza, a su vez, la propia apología de este último que desarrolla Welsch. Ciertamente, el autor se esfuerza por dar cuenta de las virtudes políticas del proceso de estetización. En este sentido, Welsch procura demostrar que la estetización de las relaciones sociales permite incrementar la sensibilidad de los sujetos frente a las diferencias y que se presenta, entonces, como un mecanismo adecuado para la formación de caracteres tolerantes y democráticos. El ámbito estético, que había sido considerado hasta el momento como un terreno exclusivo de las "almas bellas", se transformaría de este modo en un resorte indispensable para el desarrollo de auténticas cualidades democráticas.

Desde nuestra perspectiva, sin embargo, la defensa que propone Welsch de las tendencias estetizadoras actuales resulta extremadamente problemática. Esto no solo se debe al uso indeterminado que hace el autor de términos tales como "tolerancia" o "cualidades democráticas", sino también al hecho de que su propia postura es susceptible de un crítica similar a aquella que el mismo autor había realizado a la hora de cuestionar las lecturas condenatorias del proceso de estetización. Pues, si Welsch desprendía la estilización, escenificación y embellecimiento de las relaciones sociales de una estetización de los principios ontológicos que tendría lugar en el ámbito productivo, también resulta posible remitir a este último tanto la sensibilización frente a las diferencias sociales como el imperativo contemporáneo de una creación permanente de nosotros mismos. Esto es, al igual que la aparente frivolidad de las sociedades actuales, la verdadera explicación de los rasgos mencionados por Welsch se encontraría en trasformaciones que tienen su origen en el plano productivo.

Considerada desde este punto de vista, la sensibilización frente a las diferencias dejaría de presentarse como un mecanismo adecuado para promover la tolerancia entre los ciudadanos y se transformaría en un resorte necesario 
para el establecimiento de novedosas relaciones laborales y de nuevos hábitos de consumo. En lo que respecta a este último punto, la relevancia de los patrones estéticos puede observarse en el desplazamiento del valor de uso de los bienes intercambiables por el significado que adquiere la mera posición de los mismos. Pues, es el sentido estético del gusto el que permite reconocer diferencias cada vez más sutiles y el que hace posible, de esta forma, la adsorción de la creciente producción de nuevas mercancías (MENKE, 2011b, p.143). Pero tampoco el imperativo estético de una transformación creativa y permanente de nosotros mismos hace referencia "[...] a un terreno privilegiado de libertad más allá de las coacciones reproductivas" (REBENTISCH, 2012a. p.12) 9 Puesto que, como puede observarse en el mercado laboral, el mismo constituye una pieza decisiva para la autopresentación de un sujeto que debe ser comprado y utilizado por los demás bajo la forma de una mercancía. ${ }^{10}$ De esta manera, motivos estéticos tradicionales, tales como "[...] la creatividad, la espontaneidad, la originalidad", se convierten en "[...] una importante fuerza productiva del sistema capitalista": "[...] tergiversados, se transforman en exigencias sociales decisivas que, a los ojos de los individuos, se presentan más bien como un plus de coacción que de libertad." (REBENTISCH, 2012a, p.12).

\section{El DistanCiamiento eStético COMO AUTOIRONÍA}

El análisis que presentamos en el apartado anterior permite advertir hasta qué punto la defensa de una postura constructivista de carácter generalizado, como aquella que es sostenida por Welsch, conlleva la defensa de un proceso que sujeta a los individuos a la cadena productiva. Esta conclusión, no obstante, no debería conducirnos a adscribir sin más a aquellas tesis conservadoras que condenan de una manera radical el reinado omnipresente de la apariencia estética. Una lectura diferente con respecto a las dos posiciones mencionadas es la que presenta Juliane Rebentisch en su reciente libro $E l$ arte de la libertad. Para una dialéctica de la existencia democrática. Frente a aquellas perspectivas que toman como punto de partida el imperativo de una creación libre de uno mismo, la autora retoma allí la referencia hegeliana a la dependencia de la libertad individual con respecto a la propia instancia de la praxis social. Sin embargo, el objetivo de Rebentisch con consiste en reafirmar

\footnotetext{
${ }^{9}$ Para esta discusión véase MENKE; REBENTISCH (2010). Rebentisch y Menke se fundan en el estudio de Luc Boltanski y Ève Chiapello (2002).

${ }^{10}$ Una crítica diferente de posturas posmodernas similares a la de W. Welsch puede encontrarse en Fredric JAMESON (1991).
} 
de este modo la condena hegeliana de la figura "estética" de la libertad en tanto mera libertad de carácter arbitrario. A diferencia de Hegel, que descubría en aquella figura una "libertad con respecto a lo social en general", Rebentisch interpreta la disposición estética como un distanciamiento parcial con respecto a las relaciones sociales objetivas. ${ }^{11}$ El ámbito estético no promovería así "una distancia, tan abstracta como en última instancia imaginaria, con respecto a toda determinación social" sino, más bien, un distanciamiento puntual con respecto a determinados aspectos concretos que configuran la identidad social de cada individuo en particular.

Sin embargo, la estrategia de la autora no solo consiste en mostrar que las conductas estetizantes no traerían aparejada la negación de la importancia del ámbito social para la autocomprensión del individuo singular. ${ }^{12}$ Contra la crítica conservadora del reinado de la apariencia estética, Rebentisch procura demostrar, además, hasta qué punto el distanciamiento estético con respecto a las determinaciones colectivas establecidas puede ser considerado como un momento constitutivo de la propia praxis social. A tales efectos, la autora se vale de algunas teorías contemporáneas de la organización democrática que niegan el carácter natural de la unidad política y que enfatizan la importancia de una autocorrección permanente de las instituciones y de las regulaciones socialmente reconocidas. ${ }^{13}$ Pues, a la luz de estas concepciones políticas, la

\footnotetext{
${ }^{11}$ Para el análisis de la crítica de Hegel al romanticismo temprano por su tendencia estetizadora, ver: REBENTISCH (2012a, p.91-149).

${ }^{12}$ Contra aquellas posiciones antiesteticistas que interpretan las tendencias estetizadoras en términos de un voluntarismo ilimitado, Rebentisch sostiene la dependencia del propio sí mismo con respecto al acto de autodeterminación que solo puede tener lugar en el ámbito colectivo (REBENTISCH, 2012a, p.63).

${ }^{13}$ Rebentisch remite de manera explícita a Claude Lefort y Jacques Rancière a la hora de pensar el problema de la democracia (LEFORT; GAUCHET, 1971, p.7-78; RANCIÈRE, 1996). En este sentido, la autora sostiene una concepción de la democracia que no solo incorpora la crítica y revisión permanente de las determinaciones normativas establecidas, sino que presupone, además, una peculiar comprensión de lo político en general. Esta última toma como punto de partida la dependencia del sí mismo con respecto a un acto de autodeterminación y sostiene que el orden y la unidad de una comunidad son el resultado de una construcción y de una escenificación, y no elementos dados o naturales. Al respecto, sostiene Rebenstisch, "[...] a partir de la tesis de la esencia indeterminada, infundada y abierta de los miembros singulares de una comunidad se sigue que el soberano popular no puede ser pensado como presente de una manera inmediatamente positiva. El soberano popular se constituye más bien... como mediación" (2012a, p.261). De acuerdo con esta concepción de lo político, cada miembro de la comunidad política es, a la vez, un no-miembro, al menos de forma potencial. Pues, "[...] en el teatro democrático de la política, los representantes del demos se deben justificar siempre de nuevo frente a aquellos cuya voluntad pretenden representar" (REBENTISCH, 2012, p.23). Esta fundamentación de la suplementariedad del demos es expuesta por Rebentisch en otro artículo reciente (2011b, p.14s).
} 
toma de distancia reflexiva se presentarse como el presupuesto necesario tanto de "la transformación de aquella praxis social que nos determina desde el comienzo" como de "la apropiación autoafirmativa" de la misma. Dicho en otras palabras, el distanciamiento reflexivo pone en evidencia aquella diferencia con respecto a los roles socialmente estipulados en virtud de la cual resulta posible formular preguntas normativas de carácter individual y colectivo. En este sentido, concluye la autora, el esteticismo político no constituiría un "modelo para la realización vital práctica del sujeto sino más bien como un momento productivo en el marco de la misma” (REBENTISCH, 2012a, p.20).

Pero el planteo de Rebenstich no solo impide interpretar el comportamiento estético como un peligro para la esfera política, sino que contribuye a poner en evidencia, además, aquellas potenciales políticas que se hallan inscriptas en el ámbito mismo de la experiencia estética. Pues, si el distanciamiento estético con respecto al demos hace posible la institución reflexiva de la comunidad -y, con ella, la constitución de la misma en tanto comunidad de carácter político-, entonces la distancia reflexiva con respecto a la experiencia cotidiana, que tiene lugar en el plano de la recepción estética, debe presentarse también como un resorte adecuado para el desarrollo de un posicionamiento auténticamente político frente al problema de los asuntos comunes.

En este contexto, resulta necesario hacer una breve referencia a la postura de Rebentisch frente a las perspectivas estéticas de raigambre modernista. Según su opinión, el carácter problemático de estas últimas se desprendería de la incapacidad de las mismas para diferenciar la autonomía estética de la idea de una independencia de las obras con respecto al espectador. De hecho, desde el punto de vista de autores tales como Michael Fried o Theodor W. Adorno, la progresiva dependencia de las obras contemporáneas con respecto a la perspectiva preformativa del espectador supondría la subordinación de la esfera artística a un comportamiento de carácter instrumental. ${ }^{14}$ Para Rebentisch, en cambio, la concepción modernista se apresura al identificar el desplazamiento del arte contemporáneo hacia la figura del espectador con la subordinación de las obras al dominio subjetivo y no es capaz de percibir, por lo tanto, ni las motivaciones estéticas de dichas transformaciones ni el potencial crítico que se halla contenido en las mismas. En este punto la autora llama la atención acerca del hecho de que las obras de arte contemporáneo

\footnotetext{
${ }^{14}$ Para Rebentisch estos autores confunden la autonomía del arte con "[...] la ilusión de un ser para sí de las obras completamente independiente del espectador" (2003, p.57ss). Desde la perspectiva de la autora, la experiencia estética debe ser comprendida, en cambio, como "un proceso que tiene lugar entre el sujeto y el objeto" (REBENTISCH, 2003, p.12).
} 
no solo tornan necesaria la atribución de un sentido por parte del espectador, sino que frustran, además, toda posible cristalización de tales significaciones. ${ }^{15}$ Definiendo la especificidad de la experiencia estética en términos de una oscilación ininterrumpida entre el carácter cósico y significante del objeto estético, Rebentisch sostiene:

\begin{abstract}
El arte es relevante socialmente en función de su propio principio autónomo; es decir, en la medida en que la tensión entre la representación y lo representado, que es constitutiva de aquel, alcanza todos los contenidos hasta el punto de que la supuesta autoevidencia de los mismos es agotada por la lógica procesual de las obras experimentadas -incluso allí dichos contenidos se presentan como lo esencial para sus productores. Justamente en esto consiste el potencial social del arte, esto es, en el hecho de que interrumpe el enardecimiento práctico e inmediato a favor de un distanciamiento reflexivo, y no en el intento ciego, no solo desde un punto de vista estético sino también político, de intervenir políticamente por medio de él. (2003, p.278).
\end{abstract}

En este sentido, el comportamiento estético no podría ser asociado con la confirmación de la soberanía subjetiva frente a toda instancia de carácter objetivo. Sin embargo, el mismo tampoco debería ser interpretado como un acontecimiento de orden estrictamente privado. Puesto que, aun cuando la experiencia estética presuponga un comportamiento reflexivo con respecto a representaciones de orden subjetivo, la problematización de las mismas permite poner en cuestión aquella praxis colectiva en el marco de la cual dichas representaciones son establecidas y reconocidas como tales. "Por medio de ellas", concluye la autora, "yo modifico la praxis de la cual formo parte" (REBENTISCH, 2003, p.83).

De forma tal que si la democracia necesita de permanentes correcciones, la esfera estética se presenta como un escenario particularmente propicio para el desarrollo de una toma de distancia experimental con respecto a las

\footnotetext{
${ }^{15}$ Rebentisch toma como forma paradigmática del arte contemporáneo la instalación. Sin embargo, desde la perspectiva de la autora, tanto las tendencias desdiferenciadoras que se hallan presentes en las instalaciones contemporáneas como la referencia constitutiva de las mismas a la figura del espectador, actualizarían problemas fundamentales del arte moderno en general (Cf. REBENTISCH, 2003, p.8). Según puede inferirse de la investigación que desarrolla Rebentisch, estos problemas se hallarían asociados a la "doble presencia, como cosa y como signo" (REBENTISCH, 2033, p.55) de las obras de arte. Esta doble presencia se haría particularmente visible en las obras minimalistas en la medida en que la presencia antropomórfica de las mismas colocaría al espectador ante la necesidad de producir un sentido que es permanentemente subvertido por la propia naturaleza cósica de las obras (REBENTISCH, 2003, p.74).
} 
determinaciones normativas establecidas. El sujeto estético o autoirónico, concluye así la autora:

[...] contradice con sus autodeterminaciones repetidas toda reducción ética de la libertad que se produzca tanto desde una teoría de la eticidad como desde una teoría de la interioridad. Aquel solo se produce a sí mismo en un intercambio vivo con el mundo en el cual se abre la posibilidad de una apropiación libre de la praxis de la cual ya forma parte. Esta posibilidad surge en aquellos momentos que se apartan de su comprensión habitual de sí mismo y del mundo, en momentos, esto es, en los cuales ya no hay ninguna subjetividad en sí misma completa, ningún sujeto soberano. (2012a, p.216). ${ }^{16}$

\section{CONSENSO Y NEGATIVIDAD}

Si bien es posible inscribir las reflexiones de Juliane Rebentisch acerca del proceso de estetización en el marco de la teoría crítica, las mismas se caracterizan por discutir los rasgos totalizadores de la crítica adorniana y horkheimeriana del pensamiento racional. En este punto, las consideraciones de Rebentisch se hallan marcadas por la diferenciación del concepto de verdad que había trazado Jürgen Habermas desde un enfoque pragmático universal en su Teoría de la acción comunicativa ${ }^{17}$. Antes que nada, esto último puede observarse en la concepción de la democracia que defiende la autora, en la medida en que, abandonando toda perspectiva de carácter utópico, la misma se concentra en las posibilidades transformadoras que se hallarían inscriptas

\footnotetext{
${ }^{16}$ Como resulta evidente, este modo de entender el fenómeno de la estetización de la política invierte los términos en que este fue presentado por sus críticos hacia comienzos del siglo XX. Ya no se trataría de introducir en la realidad logros estéticos pasados, a los fines de generar efectos en la masas, como sostenía Benjamin (BENJAMIN, 1991, p.469), sino de incorporar al arte elementos que, en principio, no serían propios del mismo. Es esta tendencia hacia la superación y el cuestionamiento de límites artísticos la que haría posible aquel distanciamiento que permitiría pensar la politicidad inmanente de lo específicamente artístico (Cf. REBENSTISCH, 2012a, p.360).

${ }^{17}$ Desde la perspectiva habermasiana, la autonomización de las formas de organización social, en la cual Adorno y Horkheimer habían creído advertir la consumación de una lógica de dominio de la naturaleza, se presentan como productos sociales de la racionalización del mundo de la vida. En este contexto, el problema no sería, para Habermas, la existencia sin más de formas de organización conforme a fin sino más bien el hecho de que las mismas se inmiscuyan en aquellos espacios sociales que requieren de los proceso de entendimiento comunicativo. Dicho en otras palabras, el problema sería la "colonización del mundo de la vida": "La racionalización del mundo de la vida hace posible un crecimiento de la complejidad del sistema, la cual se hipertrofia hasta el punto los imperativos sistémicos liberados hacen estallar la capacidad de comprensión del mundo de la vida que es instrumentalizado por ellos" (HABERMAS, 1981/II, p.232s)
} 
en la propia esfera de la acción comunicativa. ${ }^{18}$ Pero la crítica de Habermas a la absolutización de la razón identificante, no solo le permite a Rebentisch desprenderse de la utopía adorniana de lo radicalmente otro para repesar el potencial transformador de las relaciones intersubjetivas. Pues, sobre la base del argumento habermasiano, la autora puede abandonar una concepción estética que se hallaba centrada en la obra de arte y acercarse a otra que lo hace en la relación que se establece entre la obra y el espectador. Es que, una vez reconocidas las potencialidades de liberación contenidas en el habla, ya no resulta necesario salvaguardar la fuerza crítica de la esfera estética por medio de un distanciamiento radical, como aquel que introducía Adorno a través del concepto de obra de arte negativa.

Sin embargo, tanto la lectura que realiza Rebentisch de las sociedades democráticas contemporáneas como su interpretación del potencial político de la dimensión estética se distancian de la posición habermasiana en algunos puntos importantes. La primera diferencia remite a las consecuencias que extrae la autora de su diagnóstico con respecto a las tendencias posdemocráticas que operan en el marco de las sociedades democráticas occidentales. En este punto, Rebentisch no se limita a constatar el desplazamiento de las sociedades avanzadas hacia una regulación administrativa de los asuntos comunes, sino que se esfuerza por analizar, además, las formas peculiares de visibilidad que se hallan implicadas en las lógicas de gobierno mencionadas. En términos generales, sería posible afirmar que la noción de "posdemocracia" hace referencia aquí al progresivo debilitamiento de las formas representativas de legitimación política -como aquellas que operaban en el marco de los estados nacionales modernos- y al reemplazo de las mismas por consideraciones relativas a la eficiencia de las instituciones a la hora de resolver determinados problemas de la población (SCHARPF, 1999, p.6s; CHIGNOLA, 2007, p.117 - 141; KRAUS, 2004, p.558-567).

Sin embargo, no es la mera reducción de la racionalidad práctica a una lógica de carácter instrumental, o la conversión de los ciudadanos al estatus pasivo de consumidores, lo que resulta problemático para Rebentisch. Más allá de este hecho, que ya había sido señalado por Habermas, ${ }^{19}$ la autora llama la atención acerca de la neutralización del conflicto político que trae aparejada

\footnotetext{
${ }^{18}$ Rebentisch sigue en este punto el trabajo de Albrecht Wellmer (Cf. WELLMER, 1985, p.21).

${ }^{19}$ A este tipo de cambios en el marco de las democracias representativas había hecho referencia Habermas ya en Los problemas de legitimación en el capitalismo tardio (Cf. HABERMAS, 1973, p.55). Incluso durante los últimos años, y en conexión con la crisis del euro, Habermas advierte acerca de los peligros de las formas posdemocráticas (Cf. HABERMAS, 2011).
} 
la transformación de las acciones de gobierno en mecanismos destinados a controlar y a reducir los umbrales de riego social. Desde su punto de vista, esta tendencia de las formas gubernamentales actuales torna particularmente anacrónico el énfasis de habermasiano en el ideal moderno del entendimiento intersubjetivo. En este sentido, la autora no solo encontraría problemático el compromiso de Habermas con la utopía de la transparencia y de la autenticidad social, sino también el hecho de que los motivos centrales de la misma hayan sido incorporados, entretanto, al propio discurso neoliberal. De hecho, la posibilidad de una despolitización integral de las acciones de gobierno resulta dependiente de la identificación tendencial de las formas actuales de organización social con una "sociedad sin clases" (REBENTISCH, 2007, p.122), esto es, con una sociedad que se encontraría en condiciones de ofrecerle a la totalidad de sus miembros un espacio adecuado para el desarrollo pleno y creativo de sí.

Rebentisch ve reflejada esta tendencia a una neutralización radical del conflicto social en los modos de representación pública que son asumidos en el marco de los gobiernos neoliberales actuales. Pues, si bien estos sugieren la posibilidad de una aparición de todos y de cada uno en el espacio público, lo hacen de tal manera que desactivan el carácter político de la visibilidad alcanzada. Siguiendo el análisis de Jacques Rancière, la autora hace referencia a la instauración de mecanismos de representación que tienden a individualizar la aparición pública de los ciudadanos y que, al tornar imposible la emergencia de representaciones alternativas de lo general, impiden toda posible representación del conflicto social. "Cada uno puede aparecer en público pero en esta aparición con se formulan ya pretensiones relativas a otra forma de representación política de lo general. Las apariciones en público son cada vez más individualizadas y, con ello, despolitizadas" (REBENTISCH, 2012b).

Desde la perspectiva de Rebentisch, estas tendencias vuelven insuficiente, o incluso contraproducente, tanto la crítica tradicional a la sociedad del espectáculo ${ }^{20}$ como la apelación habermasiana a una comunidad de habla libre de violencia. Puesto que es el propio discurso neoliberal el que, por intermedio de la sugestión de una visibilidad general, disuelve la distancia que media entre la realidad y la representación y hace posible, de este modo,

\footnotetext{
${ }^{20}$ Rebentisch crítica aquí la contraposición que establece el politólogo Colin Crouch entre democracia y teatralidad (Cf. CROUCH, 2004).
} 
una realización pervertida de la propia utopía de la autenticidad social. ${ }^{21}$ Como resuelta evidente, el diagnóstico que realiza Rebentisch no se halla orientado a garantizar la supresión no pervertida de las distancias sociales, esto es, a anular:

[...] la distancia de la esfera pública democrática con respecto a sí misma... en el marco de las relaciones que tienen lugar entre el gobierno y la oposición extraparlamentaria... del gobierno y la oposición parlamentaria... de la política y de la prensa... de la prensa y los ciudadanos y finalmente en la relación del ciudadano con el hombre. (2011b, p.13-4).

Por el contrario, según la perspectiva de la autora, las tendencias sociales observadas imponen la necesidad de una crítica de la representación que haga honor al sentido etimológico del término y que, en vez de repetir el reconfortable sermón generalizado contra los medios masivos de comunicación, se encuentre en condiciones de exponer "de manera renovada las divisiones y agudizarlas hasta el conflicto y la distancia” (REBENTISCH, 2007, p.122).

Pero también en lo que respecta al arte Rebentisch se distancia de la postura de Habermas, en la medida en que esta incorpora la esfera estética a la propia lógica de la acción comunicativa orientada al entendimiento. Según lo entiende Rebentisch, esto último no solo atenta contra la especificidad de la experiencia estética sino que trae aparejadas consecuencias políticas de carácter problemático. Pues, así entendida, la dimensión estética asume la tarea de anticipar en el plano apariencial la utopía práctico-política de una "comunicación libre de dominio"; esto es, se convierte en una "satisfacción aparente de la vida buena, verdadera y correcta” (REBENTISCH, 2010, p.22) y comienza a ejercer, de esta forma, funciones de carácter compensatorio. En este punto, el planteo estético habermasiano se solaparía, para Rebentisch, con la concepción estética de carácter relacional que ha desarrollado Nicolas Bourriaud durante los años 90. Por cierto, ambos autores adoptan posturas diferentes frente al problema de la diferenciación de la esfera estética. Sin

\footnotetext{
${ }^{21}$ Rebentisch se vale en este punto de la caracterización que realiza Rancière del concepto de posdemocracia. "Posdemocracia, sostiene este en El desacuerdo, es la práctica gubernamental y la legitimación conceptual de una democracia posterior al demos, de una democracia que liquidó la apariencia, la cuenta errónea y el litigio del pueblo, reductible por lo tanto al mero juego de los dispositivos estatales y las armonizaciones de energías e intereses sociales. La posdemocracia, no es una democracia que haya encontrado en el juego de las energías sociales la verdad de las formas institucionales es un modo de identificación entre los dispositivos institucionales y la disposición de las partes de la sociedad y sus partes, idóneo para hacer desaparecer al sujeto y el obrar propio de la democracia. Es la práctica y el pensamiento de una adecuación total entre las formas del Estado y el estado de las relaciones sociales" (RANCIÈRE, 1996, p.129).
} 
embargo, coinciden entre sí a la hora de concebir el ámbito estético a partir del ideal de una acción comunicativa de naturaleza consensual. Dicho en pocas palabras, tanto para Habermas como para Bourriaud, el potencial crítico de las tendencias artísticas contemporáneas se encontraría depositado en la capacidad de las mismas para producir (de manera real o apariencial) ${ }^{22}$ una praxis de integración social que sea capaz de contrarrestar el influjo que ejercen sobre los individuos los poderes sistémicos instituidos.

Como resulta fácilmente inferible a partir de las consideraciones anteriormente realizadas, para Rebentisch, una interpretación tal de la esfera estética solo podría contribuir a afianzar los mecanismos de ocultamiento o neutralización del conflicto que han sido puestos en práctica por las formas posdemocráticas de gobierno. De hecho, es este el contexto en el cual cobra sentido su recuperación de la estética negativa de Adorno. Pues, la misma contribuye a tornar visibles aquellas distancias - de la esfera pública democrática con respecto a sí misma, del "[...] gobierno y la oposición extraparlamentaria... del gobierno y la oposición parlamentaria... de la política y de la prensa... de la prensa y los ciudadanos y finalmente en la relación del ciudadano con el hombre" (REBENTISCH, 2011b, p.13-4) - que se hallan amenazadas por el propio funcionamiento del sistema social.

\section{CONSIDERACIONES FINALES}

A lo largo de estas páginas hemos procurado reconstruir los argumentos por medio de los cuales Juliane Rebentisch intenta redefinir el concepto de "estetización" a los fines de rescatar los aspectos políticamente productivos de un tipo de comportamiento que había sido denostado por la tradición filosófica occidental. Como vimos, la reivindicación que propone la autora del componente estético resulta dependiente de un determinado diagnóstico acerca de las formas gubernamentales actuales, por una parte, y se traduce, por otra parte, en una peculiar concepción de la relación existente entre la dimensión artística y el ámbito político. En el primer caso, nos referimos al

\footnotetext{
${ }^{22}$ En este punto se encuentra la diferencia entre la postura de Habermas y la de Bourriaud. Pues, si aquel insiste en la autonomía de la esfera estética, el curador francés sostiene: "las obras ya no tienen como meta formar realidades imaginarias o utópicas, sino constituir modos de existencia o modelos de acción dentro de lo real ya existente, cualquiera que fuera la escala elegida por el artista" (BOURRIAUD, 2006, p.12). Una crítica similar de la postura de Bourriaud a la que realiza Rebentisch puede encontrarse en RANCIÈRE (Cf. 2010, p.71s).
} 
uso que hace Rebentisch del concepto de posdemocracia, mientras que en el segundo tenemos en mente su recuperación semiótica o comunicativa de la estética adorniana de la negatividad. El vínculo entre ambos elementos se torna evidente si tenemos en cuenta que las formas artísticas contemporáneas se caracterizan por su tendencia a desdibujar el límite existente entre el ámbito estético y no estético (REBENTISCH, 2010, p.20). Puesto que, al hacerlo, las mismas no solo problematizan el lugar seguro del espectador sino que tornan experimentable, a su vez, una distancia con respecto a lo social que resulta constitutiva de la propia dimensión política.

Sin embargo, llegados a este punto resultaría necesario preguntarnos acerca de la posibilidad de generalizar la caracterización de las formas actuales de gobierno que propone Rebentisch. En este contexto, sería de particular interés reflexionar acerca de aquellos casos en los cuales los propios rendimientos inmediatos del sistema parecen desmentir toda posible legitimación del ejercicio del poder que se oriente en función de los resultados. Ya que en tales situaciones difícilmente será encontrar aquellas formas de gestión del espacio público que han devenido habituales en las sociedades altamente desarrolladas.

Como lo ponen en evidencia algunas experiencias actuales, en las sociedades no desarrolladas no es la visibilidad despolitizadora de todos y cada uno la que ejerce la función de garantizar las acciones de gobierno, sino más bien la exageración de las disputas políticas y la consiguiente polarización de la esfera pública. Pues, ante la magnitud de las deficiencias sistémicas, solo la escenificación de un conflicto político originario parece hallarse en condiciones de asegurar la legitimidad de las acciones gubernamentales. No obstante, afirmar la posibilidad de que, en determinadas circunstancias, la radicalización del conflicto político pueda desempeñar un papel profundamente neutralización no debe conducirnos a rechazar el carácter estético (o teatral) de la política democrática. De lo que se trataría, más bien, sería de reafirmar la necesidad de un análisis que estableciera distinciones entre las diversas formas de escenificación de la vida política. Ya que la movilización forzada de la población, a la que conduce la ilusión de la inmediatez de lo político, probablemente constituya una de las formas más extrema de las actuales tendencias hacia la despolitización. 
GALFIONE, María Verónica. Esthetics and Politics. Contemporary debate about the forms of representation. Trans/Form/Ação, Marília, v. 37, n. 1, p. 223-246, Jan./Abr., 2014.

\begin{abstract}
Both from a theoretical and from a practical perspective, the phenomenon of "aestheticization" does not seem to anticipate anything particularly good. On a theoretical level, it has been linked to the crisis of discourse-oriented in terms of truth, while in the practical, has been associated with certain cultural processes that lead to the the collapse of the normative principles. Leaving aside the theoretical issues, this paper focuses on the debate on the phenomenon of the aestheticization of the political culture. First, it goes back to the history of philosophical condemnation of the aestheticization of the political sphere. In a second time, he deals with some conceptions of the late twentieth century. Subsequently, the paper seeks to advance a redescription of this problem that allows rescue a productive sense of aesthetics for political thought. For the latter, our article is based on the reflections of Juliane Rebentisch and attempts to show how the aestheticization of political life can help to develop a new concept of the same.
\end{abstract}

KEYWORDS: Aestheticization of Politics. Aesthetic experience. Reflection.

\title{
Bibliografía
}

BENJAMIN, Walter. Das Kunstwerk im Zeitalter seiner technischen Reproduzierbarkeit (Zweite Fassung). Gesammelte Schriften, Bd. VII. Frankfurt: Suhrkamp, 1991.

BOLTANSKI, Luc; CHIAPELLO, Ève. El nuevo espiritu del capitalismo. Madrid: Akal, 2002.

BOURRIAUD, Nicolas. Estética relacional. Buenos Aires: Adriana Hidalgo, 2006.

BROMBACH, Ilka et al. Einleitung. Ästhetisierung. Der Streit um das Ästhetische in Politik, Religion und Erkenntnis. Zürich: Diaphanes, 2010.

BUBNER, Rüdiger. Ästhetisierung der Lebenswelt. Ästhetische Erfahrung. Frankfurt: Suhrkamp, 1989. p. 143-156.

CASSIRER, Ernst. La filosofía de la Ilustración. México: FCE, 1981.

CHIGNOLA, Sandro. In the Shadow of the State. Governance, governamentalità, governo. In: Governance: oltre lo Stato? Soneria Mannelli: Rubettino, 2007. p. 117-141.

CROUCH, Colin. Posdemocracia. México D.F.: Taurus, 2004.

FRITHJOF, Rodi. Die Romantiker in der Sicht Hegels, Hayms und Ditheys. In: PÖGGELER, O.; A. GETHMANN-SIEFERT, A. (Ed.). Kunsterfahrung und Kulturpolitik im Berlin Hegels. Bonn: Bouvier, 1983. p.177- 198.

HABERMAS, Jürgen. Rettet die Würde der Demokratie. Franfurter Allgemeine, 4. 11. 2011. Versión digital: http://www.faz.net/aktuell/feuilleton/euro-krise-rettet-die-wuerdeder-demokratie-11517735.html. 
Legitimationsprobleme im Spätkapitalismus. Frankfurt: Suhrkamp, 1973.

. Theorie kommunikativen Handelns. Frankfurt: Suhrkamp, 1981.

HEGEL, Georg Wilhelm Friedrich. Vorlesungen über die Ästhetik I. Werke in zwanzig Bänden. Tomo XIII. Frankfurt: Suhrkamp, 1999.

Das älteste Systemprogramm des deutschen Idealismus. Werke in zwanzig Bänden. Tomo 1, Frankfurt: Suhrkamp, 1979.

. Grundlinien der Philosophie des Rechts. Werke in zwanzig Bänden. Tomo VII. Frankfurt: Suhrkamp, 1970.

HEIDEGGER, Martin. Sein und Zeit. Tübingen: Niemeyer, 1986.

. Nietzsche. Pfullingen: Neske, 1961.

HEINE, Heinrich. La escuela romántica. Trad. Román Setton. San Martín: Biblos, 2007.

JAMESON, Fredric. Postmodernism, or, The Cultural Logic of Late Capitalism, Durham: Duke University Press, 1991.

KRAUS, Peter Die Begründung demokratischer Politik in Europa. Zur Unterscheidung von Input - und Output - Legitimation bei Fritz W. Scharpf. Leviathan, 32, p.558-567, 2004.

LEFORT, Claude y Marcel Gauchet. Sur la démocratie: la politique et l'institution du social. Textures, 1971. p.2-3, 7-78.

LUKÁCS, Georg. Ästhetische Kultur. Lukács 1996. Jahrbuch der Internationalen GeorgLukács- Gesellschaft, 1997, p.13-26.

. Die Theorie des Romans. Ein geschichtsphilosophischer Versuch über die Formen der großen Epik. Darmstadt: Luchterhand, 1987.

. Die Seele und die Formen. Neuwied: Luchterhand, 1971.

. Fortschritt und Reaktion in der deutschen Literatur. Berlin: Aufbau, 1950.

MENKE, Christoph. Estética y negatividad, Buenos Aires: FCE, 2011a.

$151,2011 b$.

. Otro tipo de gusto. Ni autonomía ni consumo de masas. Enrahonar, 46, p. 137-

. Ästhetisierung. Zur Einleitung. In: BROMBACH, Ilka et al. Ästhetisierung. Der

Streit um das Ästhetische in Politik, Religion und Erkenntnis. Zürich: Diaphanes, 2010a. p.11-22.

. Subjektivität. In: BARCK, Karlheinz et al. Ästhetische Grundbegriffe Historisches Wörterbuch in sieben. Tomo V. Stuttgart/Weimar: Metzler, $2010 \mathrm{~b}$.

; REBENTISCH, Juliane (Ed.). Kreation und Depression. Freiheit im gegenwärtigen Kapitalismus. Berlin: Kadmos, 2010. 
PLATÓN. La República. Madrid: Espasa-Calpe, 1973.

RANCIÈRE, Jacques. El espectador emancipado. Buenos Aires: Manantial, 2010.

. El desacuerdo. Buenos Aires: Nueva Visión, 1996.

REBENTISCH, Juliane. Die Kunst der Freiheit. Zur Dialektik demokratischer Existenz. Frankfurt: Suhrkamp, 2012a.

Juliane Rebentisch im Gespräch über Politik und Spektakel: Eine antitheatrale Demokratie käme ihrem Ende gleich. Jungle World, $\mathrm{N}^{\circ} 34,23$ de agosto 2012b. http:// jungle-world.com/artikel/2012/34/46115.html

. Rousseaus Heterotopologie des Theaters. Trabajo presentado en el encuentro

Aufklärung und Moderne. Forschungszentrum. Laboratorium Aufklärung. Universidad de Jena, Alemania, 2011a.

. Masse - Volk - Multitude. Überlegungen zur quelle demokratischer Legitimität.

West End. Neue Zeitschrift für Sozialforschung, 2, p.3-18, 2011 b.

. Realismus heute. Kunst, Politik und die Kritik der Repräsentation. West End Neue Zeitschrift für Sozialforschung, 2, p.15-29, 2010.

. Spektakel. Texte zur Kunst. Kurzführer/Shortguide, nº6/1, p.120-122, 2007.

. Asthetik der Installation. Frankfurt: Suhrkamp, 2003.

ROUSSEAU, J. J. Carta a D’Alembert. Trad. Eduardo Rinessi y Emilio Bernini. Chile: Arcis, 1996.

RUGE, Arnold; ECHTERMEYER, Theodor. Der Protestantismus und die Romantik Zur Verständigung über die Zeit und ihre Gegensätze. Ein Manifest (1839-1840). In: JAESCHKE, W. (Ed.). Philosophie und Literatur im Vormärz. Der Streit um die Romantik (1820-1854). Meiner: Hamburg, 1999. p.192-225.

SCHARPF, Fritz. Governing in Europe: effective and democratic? Oxford University Press, Oxford, 1999.

SCHMITT, Carl. Romanticismo politico. Quilmes: UNQ, 2001.

WELLMER, Albrecht. Wahrheit, Schein, Versöhnung. Adornos ästhetische Rettung der Modernität. In: Zur Dialektik von Moderne und Postmoderne. Vernunftkritik nach Adorno. Frankfurt: Suhrkamp, 1985.

WELSCH, Wolfgang. Grenzgänge der Ästhetik. Stuttgart: Reclam, 1996.

Submissão: 19/08/2013

Aceito em: 02/12/2013: 